\title{
Impactos da pandemia no estudo e dinâmica de vida de universitários brasileiros
}

\section{Impacts of the pandemic on the study and life dynamics of brazilian university students}

Luana Pasquoto Lopes Francisco ${ }^{1}$, Cauê Biguetti Fernandes ${ }^{1}$, Natália Leal Vio ${ }^{1}$, Isabella de Oliveira Pascoal'. Marianne Ramos Feijó ${ }^{1}$, Mário Lázaro Camargo ${ }^{1 *}$

\begin{abstract}
RESUMO
A pandemia por COVID-19 vem transformando o modo de viver da população mundial, tanto pelas (milhões) de vidas perdidas, quanto pelas mudanças econômicas, culturais e sociais que têm marcado esse período. Devido ao isolamento e distanciamento social, uma das mais rápidas e eficazes medidas tomadas visando a contenção do progresso do contágio pelo novo coronavírus - o SARS-CoV-2 - a educação, no mundo todo, passou por grande período de interrupção e alteração de dinâmica, sendo estabelecido o ensino remoto como medida alternativa, o que prejudicou o desenvolvimento dos alunos que tiveram que readaptar sua forma de viver, de aprender e de produzir. O presente artigo visa discutir de que forma os estudos e a dinâmica de vida de discentes universitários foi afetada nesse contexto pandêmico e de isolamento social, ou seja, diante de uma nova realidade educacional e do risco de contágio por uma doença grave, muitas vezes fatal e ainda sem cura. Nossos achados apontam para uma preocupação especial, a saúde mental deste público, além de outros temas que devem seguir sendo estudados para favorecer a compreensão das demandas do referido público no contexto atual e, então, possibilitar que profissionais criem políticas e ações que promovam o bem-estar e a saúde mental, não só dos discentes, mas de toda a comunidade universitária.
\end{abstract}

Palavras-chave: COVID-19; Educação; Estudantes universitários brasileiros.

\begin{abstract}
The COVID-19 pandemic has transformed the way of life of the world population, both because of the (millions) of lost lives, and because of the economic, cultural and social changes that have marked this period. Due to isolation and social distancing, one of the fastest and most effective measures taken to contain the progress of contagion by the new coronavirus - SARS-CoV-2 - education, worldwide, went through a great period of interruption and change in dynamics, with remote learning being established as an alternative measure, which hampered student development making them readjust their way of living, learning and producing. This article aims to discuss how the studies and life dynamics of university students were affected in this pandemic and social isolation context, that is, in the face of a new educational reality and the risk of contagion from a serious, often fatal disease and still no cure. Our findings point to a special concern, the mental health of this demographic, also to other topics that should keep being researched, to understand of the demands of that group in the current context and enable professionals to create policies and actions that promote the well-being and mental health, not only of the students, but of the entire university community.
\end{abstract}

\footnotetext{
1 Universidade Estadual Paulista - Unesp

* E-mail: mario.camargo@unesp.br
} 


\section{INTRODUÇÃO}

No início de 2020, o governo chinês emitiu um alerta oficial à Organização Mundial de Saúde sobre a primeira morte por pneumonia, com patógenos de origem desconhecida na cidade de Wuhan (DEUTSCHE WELLE, 2020). Poucos dias depois, pesquisadores descobriram um novo vírus, que se multiplicou de forma acelerada, atingindo pessoas em diversos países e continentes. Dois meses depois, em março de 2020, a OMS declarou que o mundo se encontrava em uma situação de pandemia pelo vírus identificado como SARS-CoV-2, causador da COVID-19 (BBC, 2020; FELIPE; MEDEIROS; CAMARGO; GOULART JR., 2021).

O SARS-CoV-2 é um vírus respiratório transmitido pelo ar e, para conter sua propagação e evitar o adoecimento grave ou morte das pessoas, a maioria dos países decretou quarentena em seu território, onde foram tomadas medidas de isolamento e distanciamento social e restrições de atividades em instituições e comércios considerados como serviços não essenciais (RAMOS et al., 2020). Em diversas organizações, nos mais variados ramos de atuação e tanto as de caráter privado como as públicas, as atividades presenciais passaram a ser realizadas à distância, de forma remota e emergencial, com o auxílio das TDICs - tecnologias digitais de informação e comunicação (GOULART JR.; CAMARGO, 2021). A suspensão das atividades presenciais se estendeu também às universidades e no Brasil foi amparada pela Portaria Ministerial $n^{\circ} .343$, do MEC, no dia 17 de março de 2020:

Art. $1^{\circ}$ - Autoriza, em caráter excepcional, a substituição das disciplinas presenciais, em andamento, por aulas que utilizem meios e tecnologias de informação e comunicação, nos limites estabelecidos pela legislação em vigor, por instituição de educação superior integrante do sistema federal de ensino, de que trata o art. $2^{\circ}$ do Decreto ${ }^{\circ} 9.235$, de 15 de dezembro de 2017 (BRASIL, 2020).

No início do alastramento da pandemia pelo mundo, o Fundo das Nações Unidas para a Infância (UNICEF, 2020), publicou que cerca de $95 \%$ das crianças e dos 
adolescentes matriculados nos sistemas de ensino da América Latina e do Caribe não estavam frequentando a escola presencialmente. No Brasil, entre março de 2020 e junho de 2021 a maioria das escolas ainda se encontrava fechada. No dia 14 de agosto de 2021, segundo relatório do Ministério da Saúde do Brasil (BRASIL, 2021), foram confirmados 206.807.509 casos de COVID-19 no mundo, sendo 36.640.271 os nos Estados Unidos da América, 32.192.576 na Índia e 20.350.142 no Brasil, apontado no relatório como o terceiro país em quantidade de casos acumulados e com 568.788 pessoas mortas. Mesmo após quase um ano e meio do início das medidas de isolamento, a média de infecção no Brasil por dia encontrava-se muito alta (BRASIL, 2021) e, em junho de 2021, houve o maior registro de notificações de casos novos em um único dia: 115.228 casos (BRASIL, 2021) desde a primeira notificação oficial nacional realizada em fevereiro de 2020. Em junho de 2021, atividades presenciais ainda não tinham sido retomadas nas universidades brasileiras de forma integral devido, principalmente, ao atraso na compra de vacinas no país e à dificuldade de controle da pandemia por parte do governo federal já apontada por Sato (2020). O posicionamento, considerado negacionista, do governo federal sobre a pandemia e a precariedade das condições sanitárias em muitas cidades brasileiras contribuíram para o avanço da contaminação e do número de mortes, o que impediu a população de voltar a realizar suas atividades rotineiras de forma gradual, ocasionando restrições que se mantiveram por um tempo maior do que em muitos países (WHO, 2021; BBC News Brasil, 2021). O fechamento das escolas de ensino fundamental e médio no Brasil, por exemplo, foi um dos mais duradouros do mundo (BBC News Brasil, 2021). No caso de centros de ensino de graduação, além dos prejuízos no ensino, deve-se considerar que o isolamento social para esse grupo tem grandes consequências na construção da identidade pessoal e na construção de relações, dentre outros prejuízos às pessoas e às organizações (GOULART JR.; CAMARGO, 2021).

O ensino superior no Brasil tem um histórico de desigualdades sociais e de um processo de precarização, posto que o acesso e a permanência de estudantes de classes menos favorecidas, em especial estudantes negros pobres, sempre foi dificultado e os investimentos do governo federal tem sofrido redução contínua. A pandemia de COVID19 aumentou essas desigualdades em função da crise social/econômica, um de seus efeitos colaterais, que atingiu grande parte da população brasileira, vulnerável em diversos aspectos. Para os estudantes universitários a insuficiência de auxílios, o corte de bolsas (principalmente bolsas de permanência e moradia estudantil), a dificuldade de acesso à 
internet/computadores/e outras tecnologias mediadoras, além da necessidade de geração de renda, ampliam ainda mais a desigualdade social dentro das universidades (SCHNEIDER, 2020; LUSA et al., 2019; CHIZZOTTI; CASALI, 2020).

Para além dos impactos diretos relacionados à infecção por COVID-19, como o medo de ser infectado ou de que familiares e amigos se infectem, as próprias medidas de isolamento e contenção da pandemia também podem consistir em fatores de risco à saúde mental, especialmente se associadas à falta ou ao desencontro de informações importantes sobre saúde pública e sobre dados relacionados aos cuidados em tempos de pandemia (GOULART JR.; CAMARGO, 2021). Algumas consequências das medidas de isolamento são a redução de contato físico e social, que frequentemente causam frustração, tédio e um senso de solidão (BROOKS et al., 2020), com mudanças de rotina significativas. A perda do emprego ou atividade exercida, a diminuição da renda familiar e a falta de acesso aos meios de tecnologia também podem aumentar os níveis de ansiedade, stress e depressão, assim como outras questões multifatoriais que se fazem presentes na vivência dos discentes (BROOKS et al., 2020).

A partir do exposto acima, considerou-se necessária a realização de um estudo com graduandos do país, para entender quais foram as principais consequências causadas pela pandemia em sua rotina e em seus estudos, à luz de questões relacionadas à saúde mental de jovens e de universitários.

\section{OBJETIVOS}

\section{1 - Objetivo Geral}

Este artigo visa discutir os impactos da pandemia por COVID-19 nos estudos e na rotina de universitários de instituições brasileiras, públicas e privadas, pautado em resultados de pesquisas realizadas sobre impactos da pandemia, condições de vida, de saúde mental e na rotina de universitários, docentes e familiares de ambos.

\section{2 - Objetivos Específicos}

A pesquisa visa também: verificar como os alunos do Ensino Superior de instituições públicas e privadas têm se adaptado para conciliar os estudos remotos e os serviços domésticos de cuidados com a casa e com os membros da família; identificar 
mudanças ocasionadas pela pandemia no vínculo, renda, modo de realizar/organizar a rotina de estudos dos discentes; investigar mudanças decorrentes da pandemia nas relações familiares e/ou com amigos e nas rotinas no lar; investigar vulnerabilidades e potencialidades desses sujeitos e suas famílias e/ou amigos na pandemia.

\section{MÉTODO, INSTRUMENTOS E PÚBLICO}

\section{1 - Tipo de Pesquisa}

Foram realizadas pesquisas descritivas, de caráter transversal exploratório, com levantamento de dados qualitativos e quantitativos, sobre os impactos de uma situação pandêmica, sem precedentes, em discentes e docentes do ensino superior das reder pública e privada brasileiras.

\section{2 - Participantes}

Participaram da pesquisa com discentes universitários, 200 alunos de diversas instituições de ensino superior do Brasil. Os critérios de inclusão para os participantes foram: possuir mais de 18 anos; concordar com os procedimentos da pesquisa e manifestar aceite através de assinatura do TCLE - Termo de Consentimento Livre e Esclarecido; ser discente regulamente matriculado em curso de graduação de alguma instituição pública ou privada brasileira.

\section{3 - Instrumentos}

Para a coleta de dados, realizada após aprovação do projeto de pesquisa junto a um CEP - Comitê de Ética em Pesquisa, foi utilizado um questionário adaptado de pesquisa realizada com docentes (VIO et al., 2021). Este questionário foi divulgado via e-mail e/ou redes sociais, por um aplicativo de formulários intitulado Google Forms, além de traduzido e adequado à língua espanhola, para futura aplicação com discentes do ensino superior da Colômbia e México² ${ }^{2}$ O instrumento também foi utilizado por Souza (2021) e revisto para aplicação com alunos do ensino médio brasileiro (SARZI, 2021).

2 Essa etapa da pesquisa encontra-se em andamento. 


\section{4 - Procedimentos de Coleta de Dados}

A primeira seção do questionário, que contempla o Termo de Consentimento Livre e Esclarecido (TCLE), constitui-se de perguntas fechadas e abertas, contém informações sobre a pesquisa, os objetivos, benefícios e riscos, convite para a pesquisa e pedido de permissão para uso de dados. Os participantes que desejaram participar e preencheram o formulário com nome, CPF ou RG, data de nascimento e e-mail, receberam uma cópia do TCLE, conforme disposições da Resolução nº 466/12, do Conselho Nacional de Saúde. Apenas nesta primeira seção há dados de identificação dos participantes e estas informações foram retiradas e armazenadas pelos pesquisadores para evitar identificação de participantes.

Além da seção com o TCLE, o Google Forms aplicado na pesquisa possui outras quatro seções divididas por categorias: dados gerais, dados e rotina de estudos, rotina de trabalhos domésticos e informações sobre a saúde física e mental durante a pandemia.

A primeira seção de perguntas investiga dados sociodemográficos dos participantes, como: gênero, idade, área de estudo, se tem filhos ou não, renda total familiar, com quem mora, entre outras.

As outras três seções investigam temáticas como: alterações na relação com a instituição de ensino superior (IES); suporte dado pela IES nesse período de pandemia; equilíbrio entre os estudos, atividades domésticas e tempo de lazer; organização do tempo para os estudos; suporte de familiares e amigos; divisão das atividades domésticas; mudanças no âmbito da alimentação, atividade física e saúde mental; potencialidades e vulnerabilidades frente à pandemia; entre outras.

É válido pontuar que após a aprovação do Comitê de Ética em Pesquisa, foi aplicado um questionário-piloto, com três discentes que se enquadram nos critérios estabelecidos para a pesquisa, de modo a identificar possíveis melhorias no instrumento antes de iniciar a divulgação do mesmo e coleta de dados oficial. 


\section{RESULTADOS}

Os resultados apresentados e discutidos no presente artigo são parte de pesquisas multicêntricas, sobre impactos da pandemia por COVID-19 no campo da educação e do trabalho, envolvendo pesquisadores brasileiros, mexicanos e colombianos. O presente artigo apresentará e discutirá os resultados obtidos com o público discente brasileiro.

No que se refere aos discentes universitários brasileiros, 200 estudantes do ensino superior responderam ao questionário, sendo eles $75 \%$ de universidades públicas e os outros $25 \%$, de instituições privadas. Destaca-se que entre os participantes da pesquisa, $67,5 \%$ são mulheres e 32,5\%, homens; 9 em cada 10 estavam na faixa de idade entre 18 e 30 anos e cerca de 78,6\% afirmaram estar em isolamento social no momento da aplicação do questionário. Cerca de $87,5 \%$ dos participantes se declararam solteiros, $11 \%$ eram casados ou estavam em uma união estável e 1,5\% eram divorciados.

Em relação à situação socioeconômica do público-alvo, pode-se observar que a renda per capita média predominante varia entre $\mathrm{R} \$ 0,00$ a $\mathrm{R} \$ 2.090,00$, representando cerca de $67 \%$ dos respondentes. Com renda de $\mathrm{R} \$ 2.090,00$ a $\mathrm{R} \$ 3.135,00$ se enquadram $19,07 \%$ dos respondentes e, acima de três salários mínimos ${ }^{3}$ per capita, se encontram $18,55 \%$ dos participantes. Em média, os estudantes dividiam a casa com uma ou até 3 pessoas (resultado que representa 78,5\% dos respondentes). A idade média das pessoas com as quais os estudantes dividem casa girou em torno dos 40 anos, apresentando uma variação desde bebês com 4 meses até idosos com 93 anos.

Ao serem questionados sobre a presença de alguma comorbidade, transtorno ou distúrbio (seja físico ou psíquico), 33,3\% dos participantes registraram que possuem alguma doença, como apresentado na Tabela 1:

3 Valor de $\mathrm{R} \$ 1.100,00$ para 2021 (Fonte:

https://www.dieese.org.br/analisecestabasica/salarioMinimo.html) 
Tabela 1 - Distribuição geral das comorbidades entre os participantes.

\begin{tabular}{|c|c|c|}
\hline Quadro & $\mathbf{n}$ & $\%$ \\
\hline Ansiedade & 33 & $35,48 \%$ \\
\hline Depressão & 21 & $22,58 \%$ \\
\hline Asma & 7 & $7,53 \%$ \\
\hline Sopro cardíaco & 1 & $1,08 \%$ \\
\hline Bipolaridade & 1 & $1,08 \%$ \\
\hline Câncer & 1 & $1,08 \%$ \\
\hline Diabetes & 1 & $1,08 \%$ \\
\hline Dislexia & 1 & $1,08 \%$ \\
\hline Doença respiratória & 1 & $1,08 \%$ \\
\hline Epilepsia & 2 & $2,15 \%$ \\
\hline Esclerose múltipla & 1 & $1,08 \%$ \\
\hline Hipertensão & 1 & $1,08 \%$ \\
\hline Hipotireoidismo & 4 & $4,30 \%$ \\
\hline Limitação nos movimentos da perna esquerda & 1 & $1,08 \%$ \\
\hline Lesões na coluna (tratamento interrompido) & 1 & $1,08 \%$ \\
\hline Obesidade & 1 & $1,08 \%$ \\
\hline Pielonefrite recorrente & 1 & $1,08 \%$ \\
\hline Problemas gastrointestinais & 1 & $1,08 \%$ \\
\hline Problemas renais & 1 & $1,08 \%$ \\
\hline Psicológico & 1 & $1,08 \%$ \\
\hline Talassemia & 1 & $1,08 \%$ \\
\hline Transtornos alimentares & 2 & $2,15 \%$ \\
\hline Transtorno Borderline & 1 & $1,08 \%$ \\
\hline $\begin{array}{l}\text { Transtorno de déficit de atenção e } \\
\text { hiperatividade }\end{array}$ & 6 & $6,45 \%$ \\
\hline Transtorno de humor & 1 & $1,08 \%$ \\
\hline Total & 93 & 100 \\
\hline
\end{tabular}

Fonte: Os autores.

Das doenças nominadas pelos participantes, verifica-se que para 74,21\% $(\mathrm{n}=69)$ estão na categoria dos transtornos psiquiátricos, ou seja, a quantidade das doenças de ordem psíquica representa 2,6 vezes mais do que as de ordem física, presentes em 25,87\% daqueles que disseram ter alguma doença. Isso mostra que, entre os entrevistados, a incidência de uma condição mental a ser tratada é mais recorrente. Sobre a frequência entre as condições psicológicas, apresenta-se a Tabela 2. 
Tabela 2 - Distribuição por comorbidades psíquicas.

\begin{tabular}{c|c|c}
\hline Quadro & $\mathbf{n}$ & $\mathbf{\%}$ \\
\hline Ansiedade & 33 & $49,25 \%$ \\
\hline Depressão & 21 & $31,34 \%$ \\
\hline Bipolaridade & 1 & $1,49 \%$ \\
\hline Dislexia & 1 & $1,49 \%$ \\
\hline Psicológico & 1 & $1,49 \%$ \\
\hline Transtornos alimentares. & 2 & $2,99 \%$ \\
\hline Transtorno Bordeline & 1 & $1,49 \%$ \\
\hline $\begin{array}{c}\text { Transtorno de déficit de atenção e } \\
\text { hiperatividade }\end{array}$ & 6 & $8,96 \%$ \\
\hline Transtorno de humor & 1 & $1,49 \%$ \\
\hline Total & $\mathbf{6 7}$ & $\mathbf{1 0 0 , 0 0 \%}$ \\
\hline
\end{tabular}

Fonte: Os autores.

Os principais transtornos apresentados foram os relacionados à ansiedade (50\%), tais como a síndrome do pânico e o transtorno de ansiedade generalizada. Cerca de $31 \%$ relataram quadros vinculados à depressão, tais como a participante P4 (P4 - codificação atribuída pelos autores para não identificar a participante) que relatou impacto negativo da pandemia:

Durante a pandemia precisei procurar atendimento psicológico e posteriormente psiquiátrico. Recentemente comecei a tomar antidepressivos. Minha auto-estima piorou e comecei a ter bloqueios ao realizar atividades acadêmicas ao ponto de ter crises de choro, além de perder o interesse nas atividades que eu gostava. Também comecei a sentir um desânimo que me impedia de fazer muitas coisas, além de uma sobrecarga mental.

Pode-se observar também, conforme veremos na Tabela 3, que a porcentagem dos participantes de nossa pesquisa que responderam positivamente ao fato de possuírem alguma doença é próxima aos que relataram uso diário de medicamentos (36,5\% para uso de medicamentos, sendo que $33 \%$ declararam que possuem alguma doença de ordem mental ou psicológica). A tabela abaixo apresenta a distribuição dessas medicações entre psicotrópicos (para transtornos psiquiátricos e neurológicos) de liberação controlada (tarja vermelha e alguns, preta) e outras medicações (liberação não controlada, tarja branca) para doenças somáticas ou degenerativas. 
Tabela 3 - Tipos de medicamentos utilizados pelos participantes da pesquisa.

\begin{tabular}{|c|c|c|}
\hline Tipo de medicamento & $\mathbf{n}$ & $\mathbf{\%}$ \\
\hline Psicotrópicos & 59 & $55,14 \%$ \\
\hline Outros & 47 & $43,93 \%$ \\
\hline Fitoterápico & 1 & $0,93 \%$ \\
\hline Total & $\mathbf{1 0 7}$ & $\mathbf{1 0 0 , 0 0 \%}$ \\
\hline
\end{tabular}

Fonte: Os autores.

Vale ressaltar que $6,5 \%$ dos participantes afirmaram não possuir nenhuma comorbidade ou doença, entretanto, ao serem questionados sobre o uso de medicamentos diários, afirmaram que, sim, fazem o uso de alguma medicação (majoritariamente para doenças de origem física). Na Tabela 4 apresentamos a relação desses medicamentos e sua subsequente frequência de uso entre os que se declararam nesse sentido.

Tabela 4 - Medicamentos e frequência de uso entre os participantes da pesquisa.

\begin{tabular}{c|c|c}
\hline Finalidade do medicamente & $\mathbf{n}$ & $\mathbf{\%}$ \\
\hline Anticonvulsivante & 1 & $1,69 \%$ \\
\hline Anticonvulsivante/ antipsicótico & 4 & $6,78 \%$ \\
\hline Anticonvulsivante/ Estabilizador de humor & 6 & $10,17 \%$ \\
\hline antidepressivo/ ansiolítico & 36 & $61,02 \%$ \\
\hline Estabilizador de humor & 4 & $6,78 \%$ \\
\hline Estimulante leve do sistema nervoso central & 4 & $6,78 \%$ \\
\hline Sedativa/hipnótico & 4 & $6,78 \%$ \\
\hline Total & $\mathbf{5 9}$ & $\mathbf{1 0 0 , 0 0 \%}$ \\
\hline
\end{tabular}

Fonte: Os autores.

Mais da metade dos participantes fazia uso de medicamentos antidepressivos ou ansiolíticos, tais como inibidores seletivos da recaptação da serotonina (ISRS), antidepressivos tricíclicos, inibidores seletivos da recaptação da serotonina e noradrenalina e inibidores da recaptação de noradrenalina-dopamina (IRND).

Os medicamentos classificados como estimulantes do sistema nervoso central, associados à dopamina, correspondiam a tarja preta, cujo uso pode ocasionar dependência psíquica e são normalmente prescritos por médicos psiquiatras. Os sedativos e hipnóticos também correspondiam à medicação de tarja preta. 
Como apenas um participante declarou possuir epilepsia, todos os medicamentos que possuíam ação anticonvulsivante estavam associados ao controle de transtornos de humor ou psicose.

Além disso, cabe informar que muitos disseram possuir transtornos psiquiátricos, contudo eles podem ou não ter recebido estes diagnósticos, tal como na fala de P21: "o ensino remoto me colocou em uma situação de estresse que nunca senti antes e sinto que deixou evidente que tenho ansiedade, embora não diagnosticada ainda". Porém as indicações medicamentosas podem comprovar os quadros descritos pela maioria dos participantes.

A autopercepção que os entrevistados apresentaram sobre a saúde mental durante a pandemia demonstra que mais da metade dos participantes (52\%) considerara sua saúde mental como ruim ou péssima e $80,5 \%$ disseram que a pandemia despertou ou piorou sentimentos e sensações negativas, como se lê nos excertos a seguir:

Teve uma piora do meu desequilíbrio emocional, improdutividade, falta de organização da minha rotina, dificuldade de acordar para fazer as tarefas (ao invés de acordar as 8/9 horas da manhã como planejado) acordo as 11/12 ou mais tarde, e deixo de realizar as atividades da manhã... por não possuir uma agenda fixa de compromissos, e trabalhar e estudar em horários maleáveis (falta de autogerenciamento e autocobrança). P8

Meu humor e sentimentos se tornaram mais instáveis, com mais altos e baixos. Percebi como coisas pequenas do dia a dia eram importantes para a saúde mental. P39

Os que consideraram sua saúde mental como regular foram $29,5 \%$ e como boa ou ótima apenas $18,5 \%$. Somente $9,5 \%$ respondeu que a pandemia despertou sentimentos e sensações positivas, enquanto os outros $10 \%$ apontaram que não houve mudanças significativas. Ao serem questionados sobre quais opções listadas sobre seus medos mais recorrentes durante a pandemia, obtivemos o seguinte resultado (Gráfico 1): 
Gráfico 1 - Principais medos/receios dos estudantes durante a pandemia.

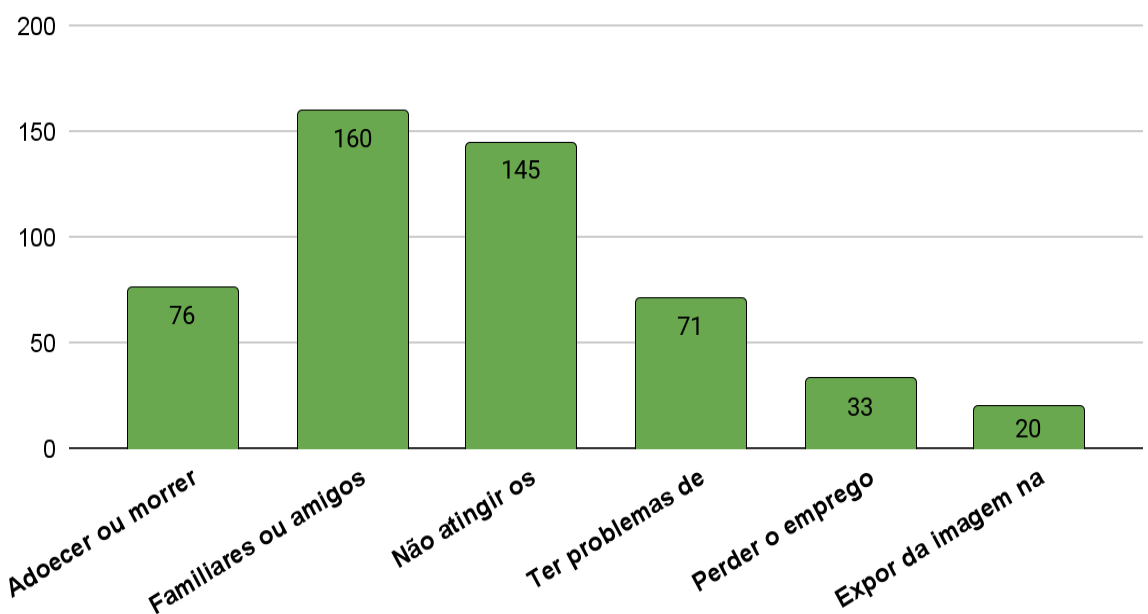

Fonte: Os autores.

Cerca de 8 em cada 10 participantes responderam que sentem medo/receio de que seus familiares ou amigos adoeçam/morram. Entretanto, apenas 38\% afirmaram que têm medo/receio de adoecer ou morrer. Por outro lado, 72,5\% dos estudantes afirmaram que têm medo/receio de não atingirem os objetivos de aprendizagem na modalidade remota e $35,5 \%$ dizem ter medo/receio de ter problemas de ordem técnica (internet, computador, plataformas).

Em relação ao medo de perder o emprego, apenas $16,5 \%$ assinalaram essa opção e somente 1 em cada 10 participantes relataram que têm medo/receio da exposição da sua imagem na internet devido a modalidade remota.

Analisando sobre as percepções que os estudantes têm sobre suas próprias casas durante a pandemia, sobre sua satisfação ao realizar atividades diárias (tais como estudar, trabalhar, praticar exercícios físicos ou descansar), observou-se que um quarto dos entrevistados responderam que estão insatisfeitos ou pouco satisfeitos na realidade que se encontram. Entre os principais motivos de insatisfação, estão a falta de espaço para exercer essas atividades, a falta de privacidade, o barulho recorrente, a falta de instrumentos para realizar essas atividades ou a mudança na rotina da casa.

Os principais aplicativos, ferramentas e tecnologias utilizados antes da pandemia pelos estudantes para se comunicar com professores e colegas eram o e-mail, o WhatsApp 
e redes sociais como Facebook e Instagram. Atualmente, eles consideram que usam, além dos meios que já utilizavam anteriormente, plataformas de vídeo chamadas como Google Meet, Zoom e Skype, além de terem utilizado mais as ligações telefônicas tradicionais.

Apenas 15\% disseram que estão insatisfeitos com a internet (em se tratando de tipo de conexão, velocidade de transmissão de dados e estabilidade) que possuem para realizar as suas atividades diárias, e ao serem questionados sobre o suporte que estavam recebendo das pessoas com quem moram, 69,04\% dos participantes responderam como bom ou ótimo, enquanto $13,09 \%$ como regular e 17,85\% como ruim ou péssimo. Por outro lado, quando questionados sobre como estão equilibrando os momentos de lazer com trabalhos domésticos, de cuidados com os membros da casa e com o ensino a distância, apenas 43,95\% dos entrevistados apontaram que estão conseguindo separar as atividades de maneira saudável e, portanto, equilibrada.

Os estudantes também relataram que dentre as opções fornecidas pela instituição de ensino durante a pandemia, a flexibilização das atividades e provas, a adaptação do conteúdo às aulas on line e o uso de ferramentas tecnológicas foram as mudanças mais recorrentes. Com menor frequência, foi comentado que a instituição de ensino ofereceu suporte psicológico.

Ao questionar os hábitos de rotina e autocuidado, como alimentação e prática de esportes, $50,5 \%$ dos entrevistados responderam que diminuíram a frequência ou pararam as atividades físicas, $21 \%$ não foram afetados pela pandemia neste sentido e $28,5 \%$ iniciaram novas atividades ou aumentaram a frequência. A alimentação também foi bem afetada para mais da metade, já que 33\% disseram que o apetite aumentou, 27,5\% apontaram que o apetite agora oscila e $12 \%$ relataram que o apetite diminuiu. Para o restante dos entrevistados, não houve mudanças significativas na alimentação.

\section{DISCUSSÃO}

A partir dos dados levantados no presente estudo, pode-se dizer que a pandemia afetou o bem-estar e a qualidade de vida dos estudantes do ensino superior no Brasil de forma geral. Ao observar a autopercepção dos alunos sobre esses fenômenos, podemos postular que a grande maioria $(80,5 \%)$ sentiu o efeito da pandemia de forma negativa, se referindo ao alto nível de isolamento social desse grupo e ao ensino remoto. Além do 
isolamento social, outras situações foram citadas pelos estudantes como sendo causadoras dessa percepção negativa sobre a pandemia: o medo de se infectar com o vírus e/ou de familiares adoecerem, o medo da perda do emprego, readaptação da rotina e as intercorrências causadas pela readaptação do ensino ao modelo remoto. Tais aspectos, entrecruzados com outros fatores estressores como a falta de contato e interação física e de apoio em relações interpessoais e institucionais - as quais geralmente funcionam como uma forma de enfrentamento de dificuldades - podem ter servido para muitos participantes como um fator de vulnerabilidade ou fragilizante, vindo a contribuir para a piora da qualidade de vida e da condição de saúde mental (DONG; ZHENG, 2020; ARDEN; CHILCOT, 2020; CULLEN; GULATI; KELLY, 2020; FELIPE; MEDEIROS; CAMARGO; GOULART JR., 2021).

A presença de comorbidades, distúrbios, doenças ou transtornos de caráter psicológico em um número elevado de entrevistados (36,5\%), acentua os efeitos sentidos desse período de pandemia e também impossibilita algumas estratégias de tratamento que dependem de atividades presenciais. Dos entrevistados, a maioria (52\%) consideraram sua saúde mental como ruim ou péssima nesse período. A medicalização, que já é muitas vezes utilizada como estratégica de enfrentamento no Brasil (MACHADO; LESSA, 2012), também é utilizada por quase todos os entrevistados que possuem alguma comorbidade, distúrbio, doença ou transtorno de caráter físico, ou psicológico, já que dos 91,2\% das pessoas nessa situação, utilizam medicação diária.

Pudemos observar que o grupo entrevistado, de forma geral, possuía os meios para seguir em suas atividades (como conexão com a internet, uso de ferramentas e equipamentos para continuação dos estudos), porém, houve um impacto considerável para grande parte dos estudantes em outros aspectos da vida, causados pelo isolamento ou distanciamento sociais, como a autopercepção predominante de sentimentos e emoções negativos nesse período. Uma diminuição nas estratégias de autocuidado como alimentação e atividades físicas, e um grande número de transtornos e distúrbios físicos e psiquiátricos com medicalização diária. Cabe ressaltar, que universitários sem acesso à internet ou aos equipamentos fundamentais para estudo durante o isolamento social ou que interromperam seus estudos, provavelmente não tiveram acesso às pesquisas. Estudos realizados com alunos de ensino médio e fundamental mostraram a gravidade da desigualdade material no país, que agrava os impactos da pandemia. Segundo o IBGE (2020), por meio de um levantamento realizado no final de 2019, quando a pandemia por 
COVID-19 ainda não havia sido decretada, mas já nos encaminhávamos para tal, estimase que 4,3 milhões de estudantes brasileiros não tinham acesso à internet, ou seja, iniciaram o período pandêmico sem esse importante recurso para dar andamento ao processo formativo em curso (em todos os níveis educacionais). À época, 20 milhões de domicílios brasileiros não possuíam internet, o que representa $28 \%$ do total.

A pandemia no Brasil, assim como para grande parte das populações, foi um evento inédito e estabeleceu uma crise sanitária de saúde imbricada em sérios problemas de acesso à renda, trabalho e educação, o que, consequentemente, aprofundou diversos problemas sociais e que se refletiu na vida de todos, em suas vivências e relações. Os estudantes universitários, que nem são do grupo mais afetado diretamente pelo vírus SARS-COV-2, se considerados dados epidemiológicos de infecção e de morte, também sentiram de forma intensa as consequências da pandemia, do isolamento social e do ensino remoto emergencial. Essas mudanças, refletiram e refletem de forma direta no processo de formação dos discentes universitários, que logo serão profissionais. Foram impactadas pela pandemia, associada ao isolamento social e os demais problemas econômicos e sociais vividos no Brasil nos anos de 2020 e 2021, a saúde mental, as relações com familiares e com amigos, portanto a construção identitária de jovens, para os quais os vínculos sociais são fundamentais (MORÉ, 2005; MORÉ; CREPALDI, 2012).

\section{CONSIDERAÇÕES FINAIS}

Os resultados da presente pesquisa mostraram diversos efeitos da pandemia por COVID-19 nos estudos e na rotina dos discentes universitários brasileiros e a necessidade de ações sociais e de saúde em diferentes níveis, inclusive macro e microssociais. O cuidado com a saúde mental de universitários é um aspecto as ser priorizado, o que envolve retomada e ampliação de oferta de serviços de saúde e de ações de prevenção. Os dados sobre uso de medicamentos e sobre a existência de doenças fornecidos por universitários participantes da pesquisa apontaram para o agravamento de suas vulnerabilidades.

Em paralelo às importantes demandas de saúde, o estudo permitiu compreender que há uma série de obstáculos que se impuseram ao processo de ensino e aprendizagem, que afetam os mais variados níveis da educação brasileira, desde educação infantil até o 
ensino superior, com maior impacto nas populações excluídas de direitos básicos. Ampliação de políticas públicas e de ações programáticas de redução de vulnerabilidade que antes da pandemia deveriam ser direcionadas com prioridade para certos grupos, no presente momento precisam alcançar uma parcela maior da população que não apresenta recursos materiais, psíquicos e sociais para enfrentamento de tão complexa situação, como a pandemia por COVID-19, considerada uma sobreposição de crises: econômica, sanitária e política.

Durante o período de pandemia em que foi realizado o estudo, não foram observadas ações significativas protagonizadas pelo Ministério da Saúde e Ministério da Educação para promover a saúde mental dos discentes brasileiros. Ao contrário, foram constatadas políticas e práticas que equivalem a um processo de desmonte das instituições de ensino superior no Brasil, fragilizando-as no sentido de continuar representando formas de suporte aos discentes. Uma análise mais ampla deve ser efetuada para entender melhor os impactos que a duração estendida da pandemia, do isolamento social e do ensino emergencial remoto podem ter causado na vida e no psiquismo desses jovens, bem como de estudantes de outras faixas etárias.

As universidades, enquanto organizações de ensino e de trabalho, na figura de seus gestores devem cuidar de discentes e de docentes, prevenindo conflitos e diferentes formas de adoecimento, inclusive sofrimento psíquico. Mas para que possa desempenhar mais essa função social, carece de sustentação, de apoio e de recursos. Algumas importantes ações internas às Instituições de Ensino Superior foram iniciadas, em caráter emergencial e remoto, mas carecem de avaliação e de investimento a médio e longo prazo. Tele-acolhimentos, ações culturais e de promoção de bem-estar e de saúde foram iniciadas em algumas universidades, paralelamente à realização de pesquisas como as aqui citadas. Porém, serviços de saúde mental, que já eram insuficientes foram reduzidos entre março e dezembro do ano de 2020, quando não, fechados, o que tornou ainda mais vulnerável a população que deles necessitam, cujo sofrimento psíquico já frequente e elevado foi agravado nos últimos meses.

A saúde mental da população em geral já carecia de melhores políticas públicas e de maior quantidade e qualificação de serviços. Os jovens são um grupo vulnerável por questões relacionadas à redução de empregos, pressões relacionadas aos estudos e à aquisição de renda. Além disso, necessitam da convivência com seus pares para 
fortalecimento da identidade e legitimação de suas escolhas. A relação familiar também é importante fonte de apoio e de legitimação, motivo pelo qual os familiares de universitários também precisam de proteção e de ações de promoção do bem-estar.

No Brasil, a enorme desigualdade social agrava o cenário e as necessidades discutidos, mas há que se reconhecer que há esforços da comunidade científica para fabricar e avaliar as vacinas, o que também exige respaldo adequado, investimento em pesquisas, redução de propagação de inverdades e importação de insumos ao mesmo tempo em que se cuida das pessoas.

Assim, em tempos de isolamento social, além das ações governamentais para acesso à saúde, alimentação, educação de qualidade dentre outros direitos, são necessárias ações institucionais e grupais. Nas universidades, atendimentos on line, manutenção de espaços de troca, redução de pressão e de carga horária de aulas em espaço virtual, planejamento pedagógico adaptado ao contexto, aumento do apoio aos discentes e docentes, inclusive para o bom uso de recursos e equipamentos para atividades on line são necessários durante a pandemia e na transição para o retorno presencial quando possível. Nas salas de aula, colegas e professores devem criar meios de conexão e de diálogo.

\section{REFERÊNCIAS}

ARDEN, M. A.; CHILCOT, J. Health psychology and the coronavírus (COVID-19) global pandemic: A call for research. British Journal of Health Psychology. Editorial. 2020. DOI: https://doi.org/10.1111/bjhp.12414

BBC. Coronavirus confirmed as pandemic by World Health Organization. BBC. 2020. Disponível em: https://www.bbc.com/news/world-51839944. Acesso em: 10 ago. 2021.

BBC News Brasil. Brasil está entre países que fecharam escolas por mais tempo na pandemia: 'É uma das decisões mais difíceis'. BBC News Brasil. 2021. Disponível em: https://www.bbc.com/portuguese/brasil-54066194. Acesso em: 11 ago. 2021.

BRASIL. Ministério da Educação. Portaria Ministerial n 343, de 17 de março de 2020. Dispõe sobre a substituição das aulas presenciais por aulas em meios digitais enquanto durar a situação de pandemia do Novo Coronavírus-COVID-19. Disponível em: https://abmes.org.br/arquivos/legislacoes/Portaria-mec-343-2020-03-17.pdf. Acesso em: 05 out. 2020. 
BRASIL. Ministério da Saúde. Secretaria de Vigilância em Saúde Doença pelo Novo Coronavírus - COVID-19. Boletim Epidemiológico Especial. 2021. Disponível em: https://www.gov.br/saude/pt-

br/media/pdf/2021/agosto/20/boletim_epidemiologico_covid_76-final20ago.pdf. Acesso em: 05 out. 2020 .

BROOKS, S. K.; WEBSTER, R. K.; SMITH, L. E.; WOODLAND, L.; WESSELY, S.; GREENBERG, N; RUBIN, G. J. The psychological impact of quarantine and how to reduce it: Rapid review of the evidence. The Lancet, v. 395, n. 10227, p. 912-920, 2020. DOI: https://doi.org/10.1016/S0140-6736(20)30460-8

CHIZZOTTI, A.; CASALI, A. M. D. Desigualdade, pobreza e diferença. Educação e $\begin{array}{llllll}\text { Filosofia, v. } \quad 34, \quad \text { n. } \quad 70, & \text { p. } & 193-222, & 2020 . & \text { DOI: }\end{array}$ https://doi.org/10.14393/REVEDFIL.v34n70a2020-49541

CULLEN, W.; GULATI, G.; KELLY, B. D. Mental health in the COVID-19 pandemic. QJM: An International Journal of Medicine, v. 113, n. 5, p. 311-312, 2020. DOI: https://doi.org/10.1093/qjmed/hcaa110

DEUTSCHE WELLE. China tem $1^{\text {a }}$ morte por misteriosa pneumonia viral. Deutsche Welle, 2020. Disponível em: https://g1.globo.com/mundo/noticia/2020/01/11/china-tem1a-morte-por-misteriosa-pneumonia-viral.ghtml. Acesso em: 10 ago. 2021.

DONG, M.; ZHENG, J. Letter to the editor: Headline stress disorder caused by Netnews during the outbreak of COVID-19. Health Expect, v. 23, n. 2, p. 259-260, 2020. DOI: 10.1111/hex.13055

FELIPE, I. F. R.; MEDEIROS, V. R.; CAMARGO, M. L.; JÚNIOR, E. G. Impactos da Pandemia de Covid-19 sobre Profissionais de Gestão de Pessoas. Revista Psicologia e Saúde, v. 13, n. 2, p. 211-225, 2021. DOI: https://doi.org/10.20435/pssa.v13i2.1558

GOULART JR; CAMARGO, M. L. Estratégias em gestão de pessoas e contribuições da Psicologia Organizacional e do Trabalho (POT) em tempos de COVID-19. In GOLUlART JR., E.; CAMPOS, D. C. (Orgs.). Gestão Estratégica de Pessoas e Psicologia Organizacional e do Trabalho. Araraquara: Letraria, 2021. Disponível em: https://www.letraria.net/wp-content/uploads/2021/04/Gestao-estrategica-de-pessoas-ePsicologia-Organizacional-e-do-Trabalho-Letraria.pdf. Acesso em: 26 ago. 2021.

INSTITUTO BRASILEIRO DE GEOGRAFIA E ESTATÍSTICAS (IBGE). PNAD Contínua - Pesquisa Nacional por Amostra de Domicílios Contínua 2021. Disponível em: https://www.ibge.gov.br/estatisticas/sociais/populacao/9171-pesquisa-nacional-poramostra-de-domicilios-continua-mensal.html?edicao $=31733 \& \mathrm{t}=$ destaques. Acesso em: 26 ago. 2021.

LUSA, M. G. et al. A Universidade pública em tempos de ajustes neoliberais e desmonte de direitos. Revista Katálysis [online]., v. 22, n. 03, p. 536-547, 2019. Disponível em: DOI: https://doi.org/10.1590/1982-02592019v22n3p536 
MACHADO, L. V.; LESSA, P. S. Medicalização da vida: ética, saúde pública e indústria farmacêutica. Psicologia \& Sociedade [online]., v. 24, n. 3, p. 741-743, 2012. DOI: https://doi.org/10.1590/S0102-71822012000300028

MAIA, B. R.; DIAS, P. C. Ansiedade, depressão e estresse em estudantes universitários: o impacto da COVID-19. Estudos de Psicologia (Campinas), v. 37, 2020. DOI: http://dx.doi.org/10.1590/1982-0275202037e200067

MORÉ, C. L. O. O. As redes pessoais significativas como instrumento de intervenção psicológica no contexto comunitário. Paidéia (Ribeirão Preto) [online]. v. 15, n. 31, p. 287-297, 2005. DOI: https://doi.org/10.1590/S0103-863X2005000200016

MORÉ, C. L. O. O.; CREPALDI, M. A. O mapa de rede social significativa como instrumento de investigação no contexto da pesquisa qualitativa. Nova Perspectiva Sistêmica, v. 21, n. 43, p. 84-98, 2012. Disponível em: https://revistanps.com.br/nps/article/view/265. Acesso em: 26 ago. 2021.

RAMOS T. H.; PEDROLO, E.; SANTANAL L.; ZIESEMER, N. B. S.; HAEFFNER R.; CARVALHO T. P. O impacto da pandemia do novo coronavírus na qualidade de vida de estudantes de enfermagem. RECOM - Revista de Enfermagem do Centro Oeste Mineiro. v. 10, 2020. DOI: https://doi.org/10.19175/recom.v10i0.4042

SATO A. P. S. Pandemia e coberturas vacinais: desafios para o retorno às escolas. Rev. Saúde Pública, v. 54, 2020. DOI: https://doi.org/10.11606/s1518-8787.2020054003142

SCHNEIDER, A. Coronavírus terá efeito colateral de ampliar desigualdade na educação: estudantes não podem ser vítimas de processo em que se finge que se ensina e se aprende. Folha de São Paulo. São Paulo, 13 jun. 2020. Disponível em: https://www1.folha.uol.com.br/educacao/2020/06/coronavirus-tera-efeito-colateral-deampliar-desigualdade-na-educacao.shtml?origin=folha. Acesso em: 05 out. 2020.

UNICEF. COVID-19: More than 95 per cent of children are out of school in Latin America and the Caribbean. UNICEF, 2020. Disponível em: https://www.unicef.org/press-releases/covid-19-more-95-cent-children-are-out-schoollatin-america-and-caribbean. Acesso em: 05 out. 2020.

VIO, N. L.; PASCOAL, I. O.; CAMARGO, M. C.; FEIJÓ, M. R.; RESTREPO, L. S. C. Impactos de la pandemia en el trabajo de los profesores universitários, Anais do CIAPOT 2021 - Congresso Iberoamericano de Psicologia Organizacional e do Trabalho. 2021. (prelo)

WANG, C.; PAN, R.; WAN, X.; TAN, Y.; XU, L.; Ho, C. Immediate psychological responses and associated factors during the initial stage of the 2019 Coronavirus Disease (COVID-19) epidemic among the general population in China. International Journal of Environmental Research and Public Health, v. 17, n. 5, p. 1729, 2020. Disponível em: https://www.mdpi.com/1660-4601/17/5/1729. Acesso em: 20 jul. 2021. 
WHO. Coronavirus Disease (COVID-19) Dashboard. WHO, 2021. Disponível em: https://covid19.who.int/. Acesso em: 20 jul. 2021.

Recebido em: 15/09/2021

Aprovado em: 10/10/2021

Publicado em: 20/10/2021 